\title{
Back to baselines: measuring change and sharing data
}

\author{
Wiebke Förch ${ }^{1 *}$, Patti Kristjanson², Laura Cramer $^{3}$, Carlos Barahona ${ }^{4}$ and Philip K Thornton ${ }^{1}$
}

\begin{abstract}
International research for development is under increasing pressure to demonstrate development outcomes that enhance people's food security and well-being while preserving the natural resource base. The CGIAR Research Programme on Climate Change, Agriculture and Food Security (CCAFS) integrates thematic research at several levels with multiple global, regional and local partners, with the aim of identifying and testing pro-poor adaptation and mitigation practices, technologies and policies for food systems, adaptive capacity and rural livelihoods. We describe a process to design and implement baselines across 2,095 households and 108 villages spread over 15 sites in 12 countries of West and East Africa and South Asia, and to archive, document and analyse the data and make them publicly available. We critically examine the process in relation to design, institutional arrangements, and partnerships. The process was long, complex and expensive. We share important lessons learned regarding how to obtain baseline data for rural populations in agricultural systems, as a basis for prioritising research and monitoring progress towards enhanced food security and increased household welfare, in part through uptake of sustainable changes in agricultural practices.
\end{abstract}

Keywords: Behavioural change, Partnership, Climate change, Food security, Africa, Asia, Livelihood, Survey methods

\section{Introduction}

Scientists project that increases in temperatures and shifts in rainfall patterns will have a significant impact on agriculture during this century. At the same time, the demand for food is increasing as the global population grows from seven billion now to a projected nine to ten billion by 2050 [1]. Food systems researchers are thus under pressure to show that they are contributing to increased food production and food security to meet this demand, along with other desired development outcomes such as improved livelihoods and environmental sustainability. Doing so will mean researchers have to shift away from the old linear 'technology transfer' model, where scientists produce new seeds and other technologies in relative isolation and simply pass them on to intermediaries such as agricultural extension services to deliver to the farmer. How to turn scientific knowledge into action at different scales effectively is still, however, far from clear $[2,3]$.

\footnotetext{
* Correspondence: w.foerch@cgiar.org

${ }^{1}$ CGIAR Research Programme on Climate Change, Agriculture and Food Security (CCAFS), ILRI, PO Box 30709, Nairobi 00100, Kenya

Full list of author information is available at the end of the article
}

Part of the challenge in designing and implementing large research projects and programmes is being able to effectively assess their performance. Tracking progress towards development outcomes requires monitoring changes in behaviour. This in turn calls for baselines that allow the measurement (or operationalisation) of change over time. While there is no shortage of surveys being carried out and data being collected, two questions are: (1) whether there is any existing information on the kinds of indicators that one can revisit, and that allow researchers to say something about the behavioural changes (or lack thereof) that are being sought; and (2) are such data likely to be available, accessible and appropriately documented in the future when required? The answer to both these questions is usually 'no'.

Many projects and programmes may find themselves in the same position as the CGIAR Research Programme on Climate Change, Agriculture and Food Security (CCAFS) was in 2010: having to design an approach aimed at convincingly showing outcomes and impacts, without pursuing standard ex-ante and ex-post economic analyses that do not accommodate partner-centric, iterative and colearning approaches [4]. In this paper, we first briefly 
describe the context of the CCAFS programme and its activities [5]. We then outline the process undertaken from 2010 onwards to design and implement baseline surveys at multiple levels in multiple sites in multiple regions of the tropics and subtropics, and to archive, document and analyse the data and make them publicly available. This is followed by a critical examination of the process in relation to three key elements: investment in design; institutional arrangements; and the importance of partnerships. We conclude with a summary of the lessons learned to date and the next steps in monitoring progress towards desirable outcomes related to food security, human wellbeing and the environment.

\section{Setting the context}

CCAFS is a research programme of the 15 international agricultural research centres of CGIAR, integrating thematic work across multiple global, regional and local partners. Its goal is to overcome the additional threats posed by a changing climate to achieving food security, enhancing livelihoods and improving environmental management. Objectives are: (1) to identify and test propoor adaptation and mitigation practices, technologies and policies for food systems, adaptive capacity and rural livelihoods, and (2) to provide diagnosis and analysis that will ensure cost-effective investments, the inclusion of agriculture in climate change policies, and the inclusion of climate issues in agricultural policies, from the sub-national to the global level in ways that bring benefits to the rural poor [5]. The programme has been designed with a strong emphasis on social differentiation and inclusiveness, particularly of women and other marginalised groups.

The context of CCAFS has several characteristics. First, the programme operates at multiple temporal scales. At shorter time scales, CCAFS is involved with promising innovations in climate risk management, as understanding how farmers are currently dealing with climate variability makes a critical contribution to thinking about actions aimed at enhancing their resilience to a different climate in the future. Over longer time scales, climate change during the coming decades is likely to significantly affect agricultural systems, and CCAFS carries out a range of activities aimed at understanding how farming households can best adapt their systems in the future (see, for example, work on 'Farms of the Future', ccafs. cgiar.org/farms-future).

Second, the programme operates at multiple spatial and institutional scales. It is designed to evaluate impact and alternative options in relation to three key indicators or outcomes: improved food security, improved rural livelihoods, and improved environmental health. CCAFS is thus meant to be a provider of intelligent reasoning concerning the many technical, informational, and policy-related options (and their synergies and trade-offs) that can be implemented, tested and scaled up to result in substantial development outcomes. The challenges posed by climate change and agriculture have to be addressed at several levels [6]. Top-down approaches may take too little account of the local situation; bottom-up approaches may miss out on the benefits arising from collective action at higher levels, and may be essentially impossible (due to cost, time, over-contextualisation) to scale up and out. Actions at one scale may have different and contradictory effects at another: for example, social welfare outcomes of particular interventions being at odds with private producer outcomes. Again, drivers operating at and across higher geographical and institutional levels will shape the feasibility of new strategies and technologies - so, for instance, global and regional markets help to define the space of possibilities for innovation and change in food systems at lower levels. A cross-scale perspective is unavoidable, and CCAFS works at levels from the household to the globe.

Third, the programme operates across wide geographical areas. Work with local communities on the ground is undertaken in 'sites' of a few hundred square kilometres, within multiple sites within a region, and in three regions of the tropics and subtropics: South Asia, East Africa, and West Africa [7]. Mini-atlases of the 15 core CCAFS sites, showing their location and some key agro-climatic characteristics, are available at http:// ccafs.cgiar.org/atlas-ccafs-sites. CCAFS has recently expanded its regional portfolio to include South-East Asia and Latin America, but baselines have not been done in these regions yet. From a climate change perspective, all regions are expected to warm; future rainfall trends are subject to considerable uncertainty, and changes in climatology in many places are not likely to be detectable for several years [8].

Within this context, CCAFS undertakes a wide range of activities. Some of these are designed to facilitate the shift towards climate-smart agricultural practices over time and space. Smallholders and others will need to change their behaviour, to make new investments and learn and try new ways of doing things, for example. CCAFS is also trying to stimulate longer-term planning, such as finding and buying improved seeds, seedlings, or livestock, or putting significant labour into soil or water management techniques, for example. Some of these interventions occur at an individual scale (such as planting drought-tolerant maize), and many require collective action (such as digging a well or water pond), which requires more attention to institutional issues. CCAFS analyses aim to be gender disaggregated and socially differentiated wherever feasible and appropriate. 


\section{Theory of Change}

Establishing causal linkages between interventions and development impacts is challenging. This is particularly true within agricultural research for development, where activities are often designed as part of a portfolio of interventions and where other causal events and conditions also contribute towards an impact. Different approaches exist to demonstrate causality, including regularity, counterfactual, comparative and generative frameworks (see [9] for a review). While the first two focus on attribution of a specific impact to an intervention, the last two address questions as to whether and how interventions have made a difference [10].

Within research for development, interventions need to be grounded in more flexible analyses of contribution rather than attribution [4]. Theory-based approaches are used to demonstrate causality while mapping causal pathways of long-term change and defining how programmes contribute to and enable the pathway towards impact [11]. Theory of Change is considered one of the most robust approaches to designing, monitoring and evaluating complex programmes, especially in the context of 'wicked' problems such as climate change [11]. The approach focuses on stakeholder engagement in articulating a flexible, larger vision of social change and systematically mapping the steps towards achieving it [12].

Within this context, CGIAR is embarking on the use of theories of change based on an understanding that these approaches are useful in the context of research for development [4]. This represents one of the major shifts within CGIAR that is currently undergoing significant institutional change. This includes not only a move towards using impact pathways and Theory of Change, but also the formation of cross-centre research programmes (of which CCAFS is one example), the need for results-based management, and the need for engagement with different partners (from the development sector, for example) in order to contribute towards development outcomes more effectively.

CCAFS activities are designed to contribute significantly to the achievement of CGIAR's system-level outcomes (http://www.cgiar.org/our-research/): reducing rural poverty, improving food security, improving nutrition and health, and sustainable management of natural resources. Programme activities on the ground are linked to these development outcomes through a set of intermediate targets arising as a result of changes in behaviour, be it a group of farmers growing a new, more droughttolerant crop, or a national agricultural research organisation mainstreaming climate information into some of their research and extension activities. A set of baseline studies was required to provide one source of evidence for some of these changes, which in turn can contribute to CGIAR system-level outcomes. One of the reasons for multi-level baselines was the recognition that it is not sufficient to focus on adoption of specific technologies and interventions at the farm level; there is also a need to build the adaptive capacities of individuals, communities and organisations to respond to climate change. Adaptive capacity and adaptation 'imply fundamental shifts in the way institutions and actors interact, value and use different types of information, how they make decisions and evaluate and respond to risks and uncertainties' ([13]: 9). CCAFS aims for integrated outcomes across all research activities in the programme's sites and regions, ranging from more local-level outcomes (such as more equitable access to and use of climate-related services and climate-resilient practices in and around our sites) to national, regional and global mainstreaming of adaptation and mitigation policies.

Recognising that changes in agricultural practices leading to enhanced food security may not happen in just a few years, at the outset of the programme and during the baseline design, we proposed revisiting the same households after roughly five years, and again in ten years, to monitor what changes have occurred since the baseline survey was carried out. The goal was not to attribute these changes to the CCAFS programme per se, as multiple partners and interventions are already underway in these sites, but to be able to assess what kinds of changes have occurred and whether these changes are helping households adapt to, and mitigate, climate change and improve their food security status.

There are considerable challenges in formulating appropriate questions to ask across highly diverse sites in different agricultural systems and different cultural, political and institutional environments. The baselines were designed to measure behavioural change within this multi-dimensional space. When starting to design the household baseline survey instrument, one of the exercises we undertook was to envision the kinds of changes we would like to see in programme sites in five to ten years' time - what would success actually look like? This is more straightforward when specific interventions or actions are known (such as drought-tolerant maize varieties, water storage technologies, payments for environmental services, and index-based insurance, for example). It is not easy to imagine what some of these interventions might be across the globe over the next decade. A key lesson here is that attention has to be paid to the underlying Theory of Change and the plausible pathways towards outcomes.

An ex-ante Theory of Change (the changes desired in programme sites after five to ten years) was developed around working with partners on three inter-dependent areas: generating evidence from action research, effecting 
policy and institutional change, and scaling up and out the technology changes needed to help smallholders adapt to climate change, mitigate greenhouse gas emissions, and better manage risk. A wide range of plausible pathways can be envisaged, including:

- The existence of some assets (or more assets) that some households did not originally own as evidence of enhanced well-being of these households, particularly assets that help households adapt to climate variability and change, such as grain storage facilities and water harvesting/storage structures to enhance household food security [14];

- More widespread ownership of information and communication technologies (ICTs) that can be used to receive weather and agricultural information helping households adapt, such as cell phones and computers [15];

- Evidence of increased diversification of livelihood strategies and new sources of income, including payments for ecosystem services such as carbon and biodiversity [16-18];

- Some evidence of a shift from subsistence to more market-oriented livelihood strategies [19];

- Evidence of crop, tree, livestock, aquaculture substitution strategies and shifts in how, what and when people plant as adaptive strategies [20];

- Evidence of new and more soil, water, and/or land management practices being implemented by more households [21];

- Evidence of improved food security situations in more, and especially in more vulnerable, households [22];

- More households (including more vulnerable ones, and women within those households) accessing and using advanced information about weather, pests and diseases [23-26];

- More households (and women) engaged in community groups that are collectively engaged in soil, water, land management and improvement activities [27,28];

- Improved access by more households to improved seeds, agricultural markets, credit for sustainable land management activities and index-based weather insurance $[29,30]$;

- Enhanced networks and linkages of community organisations engaged in natural resources management to reduce community vulnerability to climate risks and enhance their preparedness [31,32].

\section{The CCAFS baselines}

\section{Baseline survey design}

The three levels of the CCAFS baselines are shown in Table 1. The household baseline survey was designed to collect baseline information about basic household level indicators to monitor progress towards the changes described above. This included information about household size, household assets, sources of livelihood, natural resources access and management, adaptation strategies relating to crops, livestock, aquaculture, agroforestry and land management, food security and risk, sources of information, and social networks. The sample sizes were kept to a minimum and were designed so that the indicators developed would measure relatively large changes. The village baseline study was aimed at producing and mapping out gender-differentiated information about the state of natural resources, and the concerns, opportunities and vision that communities have for their environment in the future. It also provides information about the organisational landscape as perceived by the community and attempts to identify the structure and extent of information networks. The organisational baseline survey engaged with organisations that were identified during the village baseline study to gather information about the supply of services and information that those organisations give to the communities and whether climate change work is prioritised and budgeted for in local agendas. A joint analysis of the baseline data provides the opportunity to match problems, community priorities, organisations' agendas and resources, so that we can gauge the extent to which important agents contribute to addressing short- and long-term problems. This in turn will help in identifying gaps that may exist in the actions and strategies that individuals, communities and organisations take to enhance their capacity to adapt to, and reduce risks associated with, a changing climate. This is one way in which the baselines are helping CCAFS to prioritise research.

The baselines were designed in recognition of the fact that change will need to occur at different levels to create an environment that enables farmers and communities to have greater adaptive capacity and ability to manage risk. The three studies are integrated by design insofar as they share a common set of sites, a shared sampling frame, and a complementary set of survey questions. This design allows us to define a set of indicators that presents a multilayered view of conditions, resources, opportunities and constraints (Table 1).

\section{Implementation}

The number of sites, the number of survey teams involved, and the different spheres that the baselines needed to cover, highlighted the necessity of developing protocols, manuals and detailed guides for the field teams. The protocols include guidance on good research practice, including obtaining informed consent and sharing back findings (for example, household baseline survey findings were shared and discussed in public community meetings; satellite images were handed over to the community). In preparing these methodological instruments, attention was 
Table 1 Baseline studies at three levels

\begin{tabular}{|c|c|c|c|c|}
\hline Study & Scope & Methodological guides & $\begin{array}{l}\text { Analysis and } \\
\text { documentation }^{a}\end{array}$ & Key technical details \\
\hline $\begin{array}{l}\text { Household } \\
\text { level }\end{array}$ & $\begin{array}{l}\text { The household and its } \\
\text { production activities }\end{array}$ & $\begin{array}{l}\text { Field manual, analysis plan, } \\
\text { template for reporting, } \\
\text { syntax for statistical } \\
\text { software for data analysis }\end{array}$ & $\begin{array}{l}\text { Basic tabulation results, data } \\
\text { quality reports, site level } \\
\text { reports, cross-site comparison, } \\
\text { scientific papers }\end{array}$ & $\begin{array}{l}\text { One hundred and forty households ( } 20 \\
\text { households in } 7 \text { villages each) randomly } \\
\text { selected in a } 10 \times 10 \mathrm{~km} \text { sampling frame } \\
\text { (or } 30 \times 30 \mathrm{~km} \text { in areas of low population } \\
\text { density), household questionnaire }\end{array}$ \\
\hline Village level & $\begin{array}{l}\text { The community, its resources, } \\
\text { organisations and networks } \\
\text { of information }\end{array}$ & $\begin{array}{l}\text { Field manual, debriefing } \\
\text { and reporting templates }\end{array}$ & $\begin{array}{l}\text { Village-level debriefing and } \\
\text { analysis reports, data quality } \\
\text { reports, scientific papers }\end{array}$ & $\begin{array}{l}\text { Participatory, qualitative study conducted } \\
\text { in one of the seven villages from the } \\
\text { household survey, with seven groups of } \\
\text { up to fifteen men and fifteen women } \\
\text { separated to complete the various } \\
\text { exercises, participatory satellite imagery } \\
\text { interpretation }\end{array}$ \\
\hline $\begin{array}{l}\text { Organisational } \\
\text { level }\end{array}$ & $\begin{array}{l}\text { The supply of services and } \\
\text { initiatives that come to the } \\
\text { community from organisations } \\
\text { active at the site }\end{array}$ & $\begin{array}{l}\text { Field manual, reporting } \\
\text { template }\end{array}$ & $\begin{array}{l}\text { Organisational-level reports, } \\
\text { site-level summaries, scien- } \\
\text { tific papers }\end{array}$ & $\begin{array}{l}\text { At least ten organisations selected from } \\
\text { those listed by the village study } \\
\text { participants and interviewed using an } \\
\text { open-ended questionnaire }\end{array}$ \\
\hline
\end{tabular}

${ }^{\mathrm{a} A l l}$ guides and documentation are available at http://ccafs.cgiar.org/resources/baseline-surveys and http://dvn.iq.harvard.edu/dvn/dv/CCAFSbaseline.

paid to the need to maximise the possibility for comparison over time for sites as well as comparison across sites. We realised that to have a reasonable chance of gathering harmonised information in the medium and long term, all data gathering activities needed to be carefully documented. The resulting methodological guides also became the main instruments for training field teams (Table 1). The household baseline study took about 1.5 to 2 hours per household to implement, the village baseline study involved different community groups over 3 to 4 days, and the organisational baseline survey involved 1 to 2 days per site.

To date, for the CCAFS core sites, 2,095 households have been surveyed in 108 villages; 15 communities in 15 sites engaged in participatory community exercises; and over 150 organisations have been interviewed at these sites. Given the scale of the work, the baselines are broad rather than deep; the intention is that complex relationships will be explored in further research in the same locations and through the use of secondary data.

All the information collected, including data (after anonymisation), metadata, and field summaries, as well as the documentation prepared for these series of studies, is archived and publicly available on the CCAFS website and Dataverse site (http://ccafs.cgiar.org/resources/baselinesurveys and http://dvn.iq.harvard.edu/dvn/dv/CCAFSbaseline). The summaries and reports from all baselines can also be found on the CCAFS website (listed in Table 1).

The baselines are providing indicators that describe behaviour in relation to livelihood systems and farming practices through time, as well as the changes made to agriculture and natural resources management strategies in the recent past. Other indicators are helping us to understand the enabling environment that mediates these practices and behaviours (for example, natural resource conditions, policies, institutions), as well as the provision of agricultural and climatic information at each site by the organisations that work there. The purpose is to capture diversity across communities and households, while aiming for sufficient precision in some of the indicators to capture changes that occur over time. By using the same survey instruments at multiple times to monitor what changes have occurred since the baseline was carried out, we envisage that it will be possible to carry out valid and robust cross-site and cross-regional comparisons.

\section{Discussion}

\section{Baseline survey design challenges}

In many development settings, impact evaluation is increasingly being seen as contributing to an adaptive learning process that supports the successful implementation of innovative programmes [4]. This is not the case with more traditional economic impact assessment approaches that attempt to attribute outcomes to particular interventions, such as when estimating returns on investment. This also has considerable impact on baseline design, given the focus on assessing what kinds of changes have occurred and whether these changes are helping households adapt to, and mitigate, climate change. While the baselines do include some site characterisation information, there is insufficient detail for farming system characterisation in the various sites, for example. This is one of the costs of the desire to carry out cross-site and crossregional comparisons. A second cost is that if we do find changes in some of our sites through time, the baselines themselves do not contain sufficient information to attribute those changes to specific activities carried out by specific agents. 
CCAFS embraced the principle of building on local partner activities and the contributions of other research and development programmes from the outset. This implies that CCAFS's direct contribution may be quite limited at times. Instead, the aim needs to be towards filling key knowledge gaps, such as improved seasonal weather forecasts and information on practices that enhance resilience to climate change, for example. In seeking to catalyse new partnerships and strengthen existing ones, the 'contribution' approach is key, as attempts to attribute results to one particular actor or investment may be quite harmful to partnerships. While CCAFS also embraced a learning perspective at the outset, getting broader buy-in to the contribution approach earlier on in the process, and making crystal clear the linkages between the three levels of baseline, would have been particularly useful.

Two other methodological design issues are worth highlighting. First, we had considerable difficulty communicating the purpose of the baseline vis-à-vis site characterisation. Both were needed, but in CCAFS these have been separate and distinct activities; this could not have been otherwise given the scale of the baseline work. Second, answers to questions in the baseline about the reasons why households and communities have made changes in the recent past are divergent and sometimes contradictory, even for neighbouring households experiencing the same weather and climate. The influence of perceptions on past behaviour is difficult to address [33]. How this kind of information can be more effectively gathered is a research question that remains to be answered.

\section{Institutional arrangements}

Programmes such as CCAFS depend on strong, established and trusted research and implementation partners who are working closely with communities, households and individuals at the local level. These are largely local governmental and non-governmental organisations (NGOs). We needed to choose sites and design and implement baseline surveys quickly, once the programme started; the prevailing institutional arrangements meant that there was insufficient time to identify and build the strong partnerships that were ideally required. This was the case internally as well as externally. The team leading the baseline effort requested inputs into the design from diverse stakeholders within the core CCAFS team as well as broader CCAFS partners. The range of responses was wide, as there were many different areas of expertise represented and high expectations as to what could be achieved through the baselines. There was also pressure to include specific topics without a clear understanding of how the data would or could be used, and at that time there was lack of clarity on the information needs for the purposes of programme monitoring and evaluation. The team negotiated with the various stakeholders and engaged in managing the expectations to help narrow down the focus to something feasible and realistic. Of concern was not only the large amount of data that would be collected but also the time required from households and communities to answer such a wide array of questions.

The small sample size for the household survey (140 households per site) was chosen to allow for cross-site comparisons, but it does not allow for in-depth analysis within sites. This choice was made because of resource constraints and feasibility, but it caused a lack of understanding at a higher programme level. Confusion over the purpose of the baseline among stakeholders persisted during the initial years of the programme. The lesson learned from this experience is that all actors need a shared understanding and agreement at the managerial level of purpose and scope. Specifically, agreement needs to be reached on what a baseline is supposed to achieve and what it can and cannot do, so that clear objectives can be defined. While the baseline should be an integral part of the programme plan and Theory of Change, we are continuing to develop the Theory of Change as we collect information. In an ideal setting, the programme's Theory of Change would be fully formed before designing the baseline to provide the information needed.

Assembling and training teams to implement the same household survey in different places presented a range of challenges. The model used was to have one technical oversight team, along with survey teams made up of a country team leader with several enumerators. The team leaders and some enumerators from all countries were brought together for a week's joint training within each region. The objective behind this approach was to identify skilled individuals from research or other organisations whom we could work with for the next 5-10 years of the programme. An early plan was to create a network of PhD students that would lead the country survey efforts, but time pressure did not allow this. The student network approach has the advantage of better research quality oversight, because students are living in or near the sites and oversee all the work. The disadvantage is that standardisation across sites is not typically an objective, whereas writing a unique dissertation is.

\section{Partnership and capacity issues}

We strategically chose to implement baselines through the use of local partners at each site because we felt that local knowledge on the ground would be critical, and surveys were to be conducted in the local language. Building local capacity was an (ambitious) additional objective, and we wanted the knowledge generated to be used by these same partner organizations. This strategy 
had several implications: it resulted in the development of different types of partnerships in each of the three regions; it provided real challenges for capacity strengthening among partners; and it resulted in challenges in coordinating the management of the partners between the regional CCAFS teams and the team charged with technical oversight.

The regional CCAFS teams were charged with selecting the baseline implementers and building partnerships with them. Different types of partners were selected in each region. In East Africa, we worked mostly with national agricultural research services or universities. These organisations were already active in the sites and had a mandate for long-term work there. In West Africa, a regional research body was selected to undertake the baselines at all sites. This had the advantage of dealing with just one contract, but the leaders assigned to implement the surveys were at a high level in the organisation and were often stretched in terms of other responsibilities and time available. In South Asia, the baselines were implemented by consultants, who in some cases had limited local knowledge of the specific sites and were not invested in becoming long-term research partners. These different partnership models resulted in trade-offs between using a standardized approach across five regions and between flexibility in baseline design and implementation and in being mindful of social and cultural contexts. Overall, the priority was on developing and maintaining key partnerships, rather than on the research expertise and language skills of these partners. This inevitably led to different models of baseline implementation, different capacities for site-level analysis and write up of reports.

The spatial scale of the exercise in itself brought challenges in the form of working with multiple partnerships across continents. Trade-offs had to be made between implementing quickly and taking the time to build the right partnerships. For example, data from several sites in one of the regions had to be discarded because the partner failed to follow the standardized sampling procedure. The partner had been engaged for a short-term assignment, rather than being a local partner with vested interest in longer-term programme success. In addition, the partner did not have the necessary experience in conducting such surveys as part of a global team, and as a result both time and money were wasted collecting data that could not be used.

Getting buy-in from all partners was not easy. Implementing a survey across such varied sites required a standard tool, necessitating a certain level of top-down decision-making. Partners did not have the chance to contribute to the survey instrument, and so buy-in and ownership were sometimes limited. Survey instruments had to be translated into multiple languages, and there were challenges in ensuring correct interpretation across each site. Learning from the household baseline, we reduced the number of teams for the village baseline study to three regional facilitation teams (rather than country teams) that were supported by site leaders and local translators. With fewer teams, it was possible to bring everyone together for one training workshop. This allowed them to meet CCAFS staff and each other and to see that they were part of something larger than their specific site and region.

There were considerable differences in capacity among the partners in each region. In almost all cases, we underestimated the amount of capacity building necessary for achieving high-quality data collection and reporting. In sites where partners had more ownership in the process and the CCAFS programme, the outputs were of better quality and the working relationship more congenial. Where consultants were used, generally partnerships were weaker and outputs of lower quality. We observed trade-offs between experience and enthusiasm. Some partners assigned senior-level, experienced personnel to the work, who struggled to find the time to make inputs as appropriate. Other partners assigned staff with less experience but greater enthusiasm for completing the work and engaging with CCAFS on a longer-term basis.

Coordination also proved a challenge. The funding for the implementation of the baselines came from the CCAFS regional teams, while technical oversight was the responsibility of a centralised team. This arrangement undoubtedly caused some confusion among partners. It would have been prudent to assign one person within each region the clear responsibility of having full oversight over the entire baseline process.

\section{Lessons summarised, and what next}

The lessons learned to date from the CCAFS baseline work are summarised in Table 2 in the form of some recommendations. Table 2 pulls together many of the lessons that have been highlighted throughout the paper. We undoubtedly made mistakes, and the process has taken longer and been more expensive than originally anticipated. Nevertheless, a unique data set has resulted, and although its main benefits will accrue in the future, it is already being used by a wide range of people. Within CCAFS, regional comparative analyses are being written up (for example, [34]), and data from across the baseline levels are being used for internal priority setting. Externally, the survey instruments, training materials and data have been downloaded thousands of times from the Dataverse site. Several external groups are running their own analyses on the data and currently writing up the results. With the documentation that is available and the training materials online, the CCAFS 
Table 2 Lessons learned during the baseline process

When/Where Lessons

When making the case for the baseline - Ensure partners have ownership

and in the early stages of design

- Be aware of the difficulties in finding a suitable balance between the need to implement quickly and the ownership of multiple stakeholders

- Remember that quality is closely linked with ownership of the process

- Negotiate early regarding whether the baseline is to consider attribution or contribution. This has drastic implications on the design and implementation of the baseline. Contribution is a more realistic aim

- The existence of an ex-ante Theory of Change is key to negotiating scope and details of the design and implementation of the baseline. The Theory of Change needs to be made explicit early in the process, ideally jointly with the partners

- Be aware of people who at the stage of designing instruments provide input but have limited experience of collecting information in the field

- Be aware of multiple and over-ambitious information demands and the need to negotiate the scope of the baseline. The resulting baseline will inevitably be a compromise with all its disadvantages

- Work on building a core team including expert methodological support. External statistical support was useful not only technically but also for helping to manage partner relationships

- When baselines are implemented later in the process and you know your partners and your sites, it can be a good tool to build partnerships: for longer term meaningful participation of key stakeholders in research programmes and partnerships with communities themselves as key research partners and to empower them as key development actors

- As soon as the study becomes moderately complex the core team needs to assign the function of documentation and data management to an individual. If the study is large and complex a small team may be needed for this task

- Sampling design is a process that requires compromises and trade-offs. Do not assume that it can be done by one person using only statistical considerations

- Make sure there are management tools that the core team can use to provide incentives for good work and penalties for bad work

- In complex studies with multiple partners and data gathering activities, ensure that someone is given responsibility for systematization and learning

- As part of the planning process, identify specific information products, allocate responsibility for their production, and set clear deadlines

- A baseline is expected to have a follow-up in the middle or distant future. Document and store information assuming that you personally will not be involved in the follow-up. If you are, you will be pleased you did; if you are not, the objectives of the baseline will have a chance of being achieved

- In the communities, be mindful of being open about intentions, possibilities for future participation, and spaces for interaction. Be aware of not wasting people's time and make an effort to provide longer-term outcome oriented incentives for community engagement with the programme

In the field

- Train more people than you need for the field work. Offer contracts only to those who prove to be capable during the training process

- Select teams with the appropriate level and type of skills. We found a trade-off between level of experience and lack of time versus less experience and enthusiasm

- Invest in training and building capacity of field teams

- Field test thoroughly. Study designers must participate in the field testing activities

- Sort out technical questions as early as possible, such as definitions, sampling frame, and sample size

- Be aware of the requirements imposed by your choice of technology, such as the use of mobile data capturing devices such as smartphones. This has consequences on staff, skills, security, design, and data security that should not be underestimated

- Finding field teams that are good at report writing is difficult. Developing the capacity of long-term partners in both areas is key to getting good fieldwork and suitable reports. Do not underestimate the difficulties in this area

- Field team support: the provision of training, field manuals and reporting formats is important but not enough. Support through appropriate supervision and engagement during the analysis of the information 
collected is also needed. Allow enough time for report writing immediately after the information is collected in every study site

- Give community members the space to participate on their own terms, including time and opportunity to question CCAFS or the baseline and to discuss/ask questions

- Be mindful to respond to local conditions and not intrude in community space. Take seasons of heavy workload into account, consider local holidays, and so on

baselines serve as a great advertisement for the benefits of open access.

\section{Conclusions}

As many agricultural research for development organisations move towards performance-based management in the future, the importance of baselines and indicators of performance that can be tracked relatively easily will only increase. Here we have outlined a process to gather baseline indicators that will allow us to monitor progress towards desirable development outcomes in research sites across the global tropics. We started the process with an incomplete understanding of the complexities involved, and mistakes were made. If we had to do this again with the benefit of hindsight, we could probably do it in half the time at half the cost. The lessons shown in Table 2 were tough ones. However, the overarching lessons seem to us more to do with communication and learning than with the technical issues associated with measuring behavioural change through time in ways that are relatively simple, replicable, and reasonably contextindependent. Open communication, both within the program itself and with partners, and being able to clearly articulate the trade-offs among depth, scope, and detail that inevitably take place, are critical. The importance of the entire team explicitly embracing a learning approach, entailing being alert to internal and external shifts in circumstances and context, and being able to make appropriate changes and mid-course corrections without wrecking the fundamental design of the survey work, should not be underestimated. The CCAFS baseline work is ambitious, but so are the development outcomes that CGIAR and its partners are being asked to help deliver. Baseline data collection is perhaps not the sexiest research activity in the canon, but it is a critical one.

\section{Abbreviations \\ CCAFS: CGIAR Research Programme on Climate Change, Agriculture and Food Security; ICRAF: World Agroforestry Centre; ICT: Information and Communication Technology; ILRI: International Livestock Research Institute; NGO: Non-Governmental Organisation.}

\section{Competing interests}

The authors declare that they have no competing interests.

\section{Authors' contributions}

PT and PK contributed to the development of the overall approach for the CCAFS baseline as well as its role in programme monitoring and evaluation. PK, CB and WF developed the household baseline questionnaires and guidelines for implementation. WF and CB with the support of others developed the village baseline study tools and guidelines for implementation $L C, C B$ and WF with the support of others developed the organisational baseline study tools and guidelines for implementation. PK, CB, WF and LC organised and participated in the testing of the various tools in the field. WF, $\mathrm{PK}, \mathrm{CB}, \mathrm{LC}$ developed training materials and co-facilitated trainings of teams across all regions. All authors backstopped the implementation of the baselines. CB coordinated data entry and data management. PK, WF and LC supported partners in writing site level summaries of the baseline findings and edited partner reports as CCAFS technical reports. All authors helped produce cross-site summary reports of baseline data. All authors contributed to the writing of sections of this paper, have read and approved the manuscript.

\section{Acknowledgements}

Many people have been involved with the CCAFS baselines, and we are very grateful for their input: interviewers, support teams, CCAFS colleagues, householders and villagers, community leaders, and people working with many NGOs and the private sector in the various sites. We would like to especially thank the CCAFS Regional Programme teams, Ric Coe and Alois Mondondo for critical input in the early days of designing and implementing this work, and Cathy Garlick for outstanding support throughout the process. CCAFS is funded by the CGIAR Fund, AusAid, Danish International Development Agency, Environment Canada, Instituto de Investigação Científica Tropical, Irish Aid, Netherlands Ministry of Foreign Affairs, Swiss Agency for Development and Cooperation, UK Aid, and the European Union, with technical support from the International Fund for Agricultural Development.

\section{Author details}

${ }^{1}$ CGIAR Research Programme on Climate Change, Agriculture and Food Security (CCAFS), ILRI, PO Box 30709, Nairobi 00100, Kenya. ${ }^{2}$ World Agroforestry Centre, PO Box 30677, Nairobi 00100, Kenya. ${ }^{3}$ Cramer-Njihia Consultants, PO Box 2657, Nakuru 20100, Kenya. ${ }^{4}$ Statistical Services Centre, University of Reading, Whiteknights Road, Reading RG6 6FN, UK.

\section{Received: 30 January 2014 Accepted: 13 August 2014}

Published: 8 September 2014

\section{References}

1. Food and Agriculture Organization of the United Nations (FAO): Towards the future we want: end hunger and make the transition to sustainable agriculture and food systems. Rome: FAO: Policy paper for the Rio+20 Conference 13 to 22 June 2012; 2012. Available at [www.fao.org/docrep/ 015/an894e/an894e00.pdf]

2. Kristjanson P, Reid R, Dickson N, Clark WC, Romney D, Puskur R, MacMillan S, Grace D: Linking international agricultural research knowledge with action for sustainable development. Proc Natl Acad Sci U S A 2009, 9(13):5047-5052.

3. Clark WC, Tomich TP, Van Noordwijk M, Guston D, Catacutan D, Dickson NM, McNie E: Boundary work for sustainable development: natural resource management at the Consultative Group on International Agricultural Research (CGIAR). Proc Natl Acad Sci 2011. Published ahead of print on 15 August 2011. doi:10.1073/pnas.0900231108.

4. Mayne J, Stern E: Impact Evaluation of Natural Resource Management Research Programs: a Broader View, ACIAR Impact Assessment Series Report 84. Australian Centre for International Agricultural Research: Canberra; 2013.

5. Vermeulen $\mathrm{S}$, Zougmoré $\mathrm{R}$, Wollenberg $\mathrm{E}$, Thornton PK, Nelson $\mathrm{G}$, Kristjanson P, Kinyangi J, Jarvis A, Hansen J, Challinor AJ, Campbell B, Aggarwal PK: Climate change, agriculture and food security: a global 
partnership to link research and action for low-income agricultural producers and consumers. Curr Opin Environ Sustain 2012, 4:1-6.

6. Cash DW, Adger W, Berkes F, Garden P, Lebel L, Olsson P, Pritchard L, Young O: Scale and cross-scale dynamics: governance and information in a multilevel world. Ecol Soc 2006, 11(2)

7. Förch W, Sijmons K, Mutie I, Kiplimo J, Cramer L, Kristjanson P, Thornton P, Radeny M, Moussa A, Bhatta G: CCAFS Site Portfolio. East Africa, West Africa and South Asia, Volume Version 3. Copenhagen: Core Sites in the CCAFS Regions; 2013. CGIAR Research Program on Climate Change, Agriculture and Food Security (CCAFS); 2013. Available at [http://ccafs.cgiar.org/ publications/ccafs-site-portfolio-core-sites-ccafs-regions-east-africa-westafrica-and-south-asia]

8. Washington R, New M, Hawcroft M, Pearce H, Rahiz M, Karnacharya J: Testing climate models for agricultural impacts: recent trends, current projections, crop-climate suitability, and prospects for improved climate model information. Copenhagen: CGIAR Research Program on Climate Change, Agriculture and Food Security (CCAFS); 2012. Available at [http://ccafs.cgiar. org/publications/testing-climate-models-agricultural-impacts-recent-trendscurrent-projections-crop]

9. Stern E, Stame N, Mayne J, Forss K, Davies R, Befani B: Broadening the Range of Designs and Methods for Impact Evaluations, DFID Working Paper 38 London: Department for International Development; 2012. Available at: [https://www.gov.uk/government/uploads/system/uploads/ attachment_data/file/67427/design-method-impact-eval.pdf]

10. Mayne J: Making causal claims.: ILAC Brief; 2012:26. Available at: [http://www.cgiar-ilac.org/files/ilac_brief26_making_causal_claims_0.pdf]

11. Bours D, McGinn C, Pringle P: Selecting indicators for climate change adaptation programming. SEA Change CoP and Oxford: UKCIP: Phnom Penh; 2014.

12. Bours D, McGinn C, Pringle P: The Theory of Change approach to climate change adaptation programming. SEA Change COP and Oxford: UKCIP: Phnom Penh; 2014.

13. Stienecker C: CARE's Approach to Climate-Smart Smallholder Agriculture. A report prepared for Care International. Nairobi: Poverty, Environment and Climate Change Network; 2012.

14. Carter $M$, Barrett $C$ : The economics of poverty traps and persistent poverty: an asset-based approach. Dev Stud 2006, 42(2):178-199.

15. Duncombe R: Mobile Phones for Agricultural and Rural Development: A Literature Review and Future Research Directions. Centre for Development Informatics Research Paper 50. UK: Institute for Development Policy and Management, University of Manchester; 2012.

16. Krishna A, Kristjanson P, Radeny M, Kuan J, Quilca G, Sanchez-Urrelo A: Escaping poverty and becoming poor in forty communities of the Peruvian Andes. Dev Change 2006, 37(5):997-1021.

17. Food and Agriculture Organization of the United Nations (FAO): The State of Food and Agriculture. Rome: FAO: Paying Farmers for Environmental Services; 2007. Available at [www.fao.org/docrep/010/a1200e/a1200e00.htm]

18. Kristjanson P, Mango N, Krishna A, Radeny M, Johnson N: Understanding poverty dynamics in Kenya. J Int Dev 2010, 22(7):978-996.

19. Wiggins S: Can the smallholder model deliver poverty reduction and food security for a rapidly growing population in Africa?. Rome: FAO: Background Paper for the Expert Meeting on How to feed the World in 2050; 2009. Available at [www.fao.org/docrep/012/ak542e/ak542e00.htm]

20. Food and Agriculture Organization of the United Nations (FAO): Climate-Smart Agriculture Source Book. Rome: FAO: 2013. Available at [http://www.fao.org/docrep/018/i3325e/i3325e.pdf]

21. Barrett CB, Place FM: Aboud AA (Eds): Natural Resources Management in African Agriculture: Understanding and Improving Current Practices. CAB International; 2002

22. Food Security Group (FSG): Lessons learned from 25 years of food security research, capacity- building, and outreach. Michigan State University: MSU IDWP 101. East Lansing: Department of Agricultural, Food, and Resource Economics; 2009. Available at [http://ageconsearch.umn.edu/handle/55047]

23. Roncoli C, Jost C, Kirshen P, Sanon M, Ingram KT, Woodin M, Somé L: From accessing to assessing forecasts: an end-to-end study of participatory climate forecast dissemination in Burkina Faso (West Africa). Clim Change 2008, 92(3-4):433-460.

24. Barnett $B J$, Barrett $C B$, Skees JR: Poverty traps and index-based risk transfer products. World Dev 2008, 36:1766-1785.
25. Alderman $\mathrm{H}$, Haque $\mathrm{T}$ : Insurance against covariate shocks: the role of indexbased insurance in social protection in low-income countries of Africa. Washington, D.C: World Bank: In World Bank Working Paper 95; 2007.

26. Hansen JW, Mason SJ, Sun L, Tall A: Review of seasonal climate forecasting for agriculture in sub-Saharan Africa. Exp Agric 2011, 47(2):205-240.

27. Meinzen-Dick R, Knox A, Place F, Swallow B: Innovations in Natural Resource Management: The Role of Property Rights and Collective Action in Developing Countries. Baltimore: Johns Hopkins Press and International Food Policy Research Institute; 2002.

28. Meinzen-Dick R, Markelova H, Moore K: The role of collective action and property rights in climate change strategies. In CAPRi Policy Brief 7. Washington DC: International Food Policy Research Institute; 2010

29. Pender J, Place F, Ehui S: (Eds): Strategies for Sustainable Land Management in the East Africa Highlands. Washington DC: International Food Policy Research Institute; 2006.

30. McCarthy N: Demand for Rainfall-Index Based Insurance: A Case Study from Morocco, EPTD Discussion Paper 106. Washington DC: International Food Policy Research Institute; 2003.

31. Tompkins EL, Adger WN: Does adaptive management of natural resources enhance resilience to climate change? Ecol Soc 2004, 9(2):10.

32. Agarwal A: Local institutions and adaptation to climate change. In Social Dimensions of Climate Change. Washington, DC: The World Bank: Equity and Vulnerability in a Warming World. Edited by Mearns R, Norton A; 2010:173-198.

33. Rufino MC, Thornton PK, Ng'ang'a SK, Mutie I, Jones PG, van Wijk MT, Herrero M: Transitions in agro-pastoralist systems of East Africa: Impacts on food security and poverty. Agr Ecosyst Environ 2013, 179:215-230.

34. Kristjanson P, Neufeld H, Gassner A, Thornton PK, Förch W, Mango J, Kyazze F, Desta S, Sayula G, Thiede B, Kinyangi J: Are food insecure smallholder households making changes in their farming practices? Evidence from East Africa. Food Secur 2012, 4:381-397.

doi:10.1186/2048-7010-3-13

Cite this article as: Förch et al:: Back to baselines: measuring change and sharing data. Agriculture \& Food Security 2014 3:13.

\section{Submit your next manuscript to BioMed Central and take full advantage of:}

- Convenient online submission

- Thorough peer review

- No space constraints or color figure charges

- Immediate publication on acceptance

- Inclusion in PubMed, CAS, Scopus and Google Scholar

- Research which is freely available for redistribution

Submit your manuscript at www.biomedcentral.com/submit 